\title{
Synchrony effects in cognition: The costs and a benefit
}

\author{
CYNTHIA P. MAY \\ University of Arizona, Theson, Arizona
}

\begin{abstract}
The present study investigated whether younger and older adults' ability to inhibit distractors in a problem-solving task is affected by synchrony, or the match between circadian arousal periods and time of testing. Consistent with an inhibitory-deficit explanation of synchrony effects, both age groups showed heightened susceptibility to distraction at off-peak relative to peak times. In most instances, increased sensitivity to distraction disrupted problem-solving performance; however, when distracting material was related to task goals, individuals actually benefited from reduced inhibitory efficiency. The present data are also consistent with other research in showing that access to and production of well-learned or familiar responses are not vulnerable to synchrony effects.
\end{abstract}

Circadian rhythms have a broad impact on daily life, governing a number of physiological processes (e.g., Horne \& Ostberg, 1976; Hrushesky, 1994; Moore-Ede, Czeisler, \& Richardson, 1983) and influencing the ability to adapt to time changes and shift work (see, e.g., Czeisler, Johnson, Duffy, \& Brown, 1990; Folkard \& Monk, 1985; Smolensky \& D'Alonzo, 1993). Recent work suggests that circadian rhythms may also affect some types of cognitive functioning, with individual differences in circadian arousal patterns dramatically shaping performance over the day on tests of memory (May, Hasher, \& Stoltzfus, 1993; Petros, Beckwith, \& Anderson, 1990), attention (Horne, Brass, \& Pettitt, 1980; Intons-Peterson, Rocchi, West, McLellan, \& Hackney, 1998), and decision making (Bodenhausen, 1990; Yoon, 1997). The general finding in these studies is that superior cognitive functioning occurs when testing times are synchronized with individuals' peak circadian arousal periods, a finding referred to as the "synchrony effect" (May \& Hasher, 1998; May et al., 1993).

Our investigations have been aimed at identifying those cognitive processes that are most prone to synchrony effects, and those, if any, that may be relatively resistant to fluctuations in circadian arousal. One possibility explored in a number of recent studies is that inhibition, which operates to suppress irrelevant or off-task information (Hasher \& Zacks, 1988; Navon, 1989a, 1989b; Neill, 1977), may be particularly susceptible to synchrony

This work was funded by grants from the National Institute on Aging (AG0 4306 and AG12753) and by a graduate fellowship from the National Science Foundation. I thank Lynn Hasher for her invaluable input throughout this project, especially for her helpful comments on an earlier draft of this article. I am also grateful to Mary Peterson and Karen Li for their suggestions on this manuscript. Finally, I extend thanks to Michael Szarek and Dina Dicenso for their assistance at various stages of the project. Correspondence should be addressed to C. P. May. Department of Psychology, College of Charleston, 66 George St., Charleston, SC 29424 (e-mail: mayc(a)cofc.edu). effects (see, e.g., May \& Hasher, 1998; Yoon, May, \& Hasher, 1999). Inhibition is believed to serve three broad functions with respect to information processing (see, e.g., Hasher, Zacks, \& May, 1999): First, inhibition limits access to working memory, thus restricting sustained activation to only relevant, task-oriented stimuli. Second, inhibition deletes or suppresses information that was once relevant but is no longer suitable for present goals. Third, inhibition acts to restrain the production of strong responses so that they can be evaluated for their appropriateness, thus allowing for the appraisal and rejection of prepotent but undesirable responses.

Converging evidence suggests that each of these three inhibitory functions may be impaired at off-peak relative to peak times. With respect to the access function, for example, several findings are suggestive of heightened susceptibility to distraction at off-peak relative to peak times. Negative priming, which is often used to assess the inhibition of irrelevant items in a selective attention task, is significantly diminished when participants are tested at off-peak relative to peak times (Intons-Peterson et al., 1998). ${ }^{1}$ In addition, visual discrimination between targets and distractors declines (Horne et al., 1980), and Stroop (1935) interference increases (May \& Hasher, 1998) at off-peak relative to peak times. With respect to the deletion function, individuals tested at peak times are more successful than those at off-peak times in suppressing information that was once relevant but is no longer appropriate for current goals (May \& Hasher, 1998). Finally, studies examining the restraint function show that individuals have diminished control over inappropriate motor responses (May \& Hasher, 1998) and are less able to prevent highly likely but unwanted verbal responses (May, Hasher, \& Bhatt, 1994) at off-peak relative to peak times of day. ${ }^{2}$

In contrast to the data in inhibitory deficits observed at off-peak times of day, data from a number of studies demonstrate that tasks that rely on access to and production of well-learned responses, without requiring the in- 
hibition of irrelevant or marginally relevant information, seem to be relatively unaffected by synchrony (see, e.g., May \& Hasher, 1998; Yoon et al., 1999). For example, stable performance over the day has been found for category judgments, vocabulary tests, color naming, and generation of highly probable sentence endings (see, e.g., Li et al., 1998; May \& Hasher, 1998; Yoon, 1997). Together, the patterns of impaired versus spared functioning suggest that it is the inhibition rather than the production of strong, familiar, or highly accessible responses that diminishes at off-peak times.

The present work adds to this literature by examining the effect of synchrony on problem-solving performance in the presence versus absence of distraction. One aim of this research is to assess the viability of an inhibitory framework for understanding synchrony effects on cognition in terms of predicting both heightened access to distraction at off-peak relative to peak times and stable performance over the day in the absence of distraction. A second aim of this research is to investigate the possibility that there may be circumstances in which heightened susceptibility to distraction might be beneficial-that is, when the distracting material happens to prompt the correct answer. Consider, for example, the familiar experience of abandoning a difficult problem out of frustration, only to be struck with the solution by some seemingly unrelated event (which, in fact, is associated with the solution). Is it possible that heightened awareness to distraction might actually produce a benefit in certain circumstances?

To address these two aims, the present study examined problem-solving performance in the presence and absence of distraction using word problems from the Remote Associates Test (RAT; Mednick, 1962). Problems on the RAT consist of three cue words (e.g., SHIP, OUTER, CRAWL), each of which is associated to the same target word (e.g., SPACE: spaceship, outer space, crawl space). Participants' task is to identify the target word that connects the three cue words. Previous research demonstrates that presenting misleading distractors (i.e., distractors unrelated to the target) with the cue words (e.g., SHIP [ocean], OUTER [inner], CRAWL [floor]) significantly impairs identification of the critical target (S. M. Smith \& Blankenship, 1991). The present study thus included trials with misleading distractors, with the expectation that performance on misleading trials would be disrupted relative to that on control (no-distractor) trials, particularly so for individuals tested at off-peak times. In addition, trials containing related, "leading" distractors (which associated the cue words to the target; e.g., SHIP [rocket], OUTER [atmosphere], CRAWL [attic]) were also included to explore the possibility that enhanced susceptibility might be beneficial when distractors are related to the target solution.

Performance on the problem-solving task over the day was examined with both younger and older adults. An age comparison was included for several reasons. First, relative to younger adults, older adults demonstrate relatively inefficient inhibitory processing (e.g., Hasher \& Zacks, 1988; McDowd, Oseas-Kreger, \& Filion, 1995;
Zacks, Radvansky, \& Hasher, 1996; but see Burke, 1997), and thus this age comparison enabled an examination of synchrony effects on inhibition for two groups with baseline differences in inhibitory processing. Second, strong evidence suggests there are age differences in peak arousal periods, with many younger adults being evening types and most older adults being morning types (e.g., Adan \& Almirall, 1990; Intons-Peterson et al., 1998; May \& Hasher, 1998; Mecacci \& Zani, 1983). This difference in peak periods across age groups suggests that the magnitude of age differences may vary over the day, with minimal differences in the morning, when older but not younger adults are at their peak, and robust, potentially exaggerated differences in the evening, the peak for younger but not older adults. Indeed, several previous findings are consistent with this prediction (see, e.g., May \& Hasher, 1998; May et al., 1993), and thus the present work investigated the stability of age differences in performance across the day.

\section{METHOD}

\section{Participants}

Forty younger adults (ages $18-25$ years) and 48 older adults (ages $60-75$ years) participated in this study. Younger adults were college students at the University of Arizona who participated for course credit; older adults were healthy, well-educated communitydwelling volunteers from Tucson, Arizona, who received nominal compensation for their participation.

Participants were selected to have peak performance periods that were consistent with general age norms (see, e.g., Intons-Peterson et al., 1998; May \& Hasher, 1998); that is, all younger adults were evening types, and all older adults were morning types. The fully crossed design of age $\times$ morningness-eveningness was simply impossible because so few of the younger adults were morning types and, as with numerous other normative studies (Adan \& Almirall, 1990; May \& Hasher, 1998; Mecacci, Zani, Rocchetti, \& Lucioli, 1986), almost none of the older adults were evening types. Circadian arousal patterns for our participants were determined with the Morningness-Eveningness Questionnaire (MEQ; Horne \& Ostberg, 1976), a paper-and-pencil survey that has been used extensively to assess individual differences in circadian arousal patterns (see, e.g., Buela-Casal, Caballo, \& Cueto, 1990; Horne \& Ostberg. 1976; Petros et al., 1990). Scores on the MEQ classify individuals as one of three general types: evening types (scores of 16-41), neutral types (scores of 42-58), and morning types (scores of 59-86). These scores show strong correlations with a number of behavioral and physiological measures of arousal, including arising time, body temperature, basal skin conductance, and heart rate (Adan, 1991; Horne \& Ostberg, 1976; Kerkhof, van der Geest, Korving, \& Rietveld, 1981), and the questionnaire provides a valid and reliable measure of individual differences in circadian arousal (Kerkhof, 1984; C. S. Smith, Reilly, \& Midkiff, 1989).

\section{Materials}

Forty word problems, each consisting of three cue words that were remotely associated to the same target, were adapted from those developed by Mednick (1962) and S. M. Smith and Blankenship (1991) for use as critical items in this study. In addition, 10 additional problems were developed as fillers. Each of the problems had one and only one solution, and none of the problems had the same solution. The 10 filler items were created to be relatively easy to encourage participants (e.g., (A.NDY, SUGAR, WALKING = CANE), becausc pilot testing indicated that the original 40 items were rela- 
Table 1

\begin{tabular}{|c|c|c|c|c|c|c|c|}
\hline \multirow[b]{3}{*}{ Group } & \multirow[b]{3}{*}{ Testing Period } & \multicolumn{6}{|c|}{ Trial Type } \\
\hline & & \multicolumn{2}{|c|}{ Control } & \multicolumn{2}{|c|}{ Misleading } & \multicolumn{2}{|c|}{ Leading } \\
\hline & & $M(\%)$ & $S D$ & $M(\%)$ & $S D$ & $M(\%)$ & $S D$ \\
\hline \multirow[t]{2}{*}{ Young (evening types) } & Peak & 35 & 16.7 & 33 & 16.0 & 36 & 19.0 \\
\hline & Off-peak & 33 & 17.2 & 22 & 13.3 & 50 & 22.4 \\
\hline \multirow[t]{2}{*}{ Old (morning types) } & Peak & 33 & 18.4 & 23 & 11.3 & 41 & 20.5 \\
\hline & Off-peak & 36 & 10.0 & 18 & 10.8 & 59 & 16.7 \\
\hline
\end{tabular}

tively difficult (e.g., $M$ solution rate $=32 \%$ ). Pilot testing with the filler items indicated that they had a relatively high solution rate $(M=70 \%)$.

For each of the 40 critical problems, one set of misleading distractors and one set of leading distractors were developed. Pilo testing indicated that relative to control (no-distractor) trials, intentionally attending to the misleading and leading distractors led to reliably lower and greater solution rates, respectively, for both age groups.

For the actual experiment, each participant attempted 50 problems ( 40 critical and 10 filler). All 10 filler items appeared without distraction. Ten of the critical problems were also no-distractor (control) items; 20 included misleading distractors, and 10 included leading distractors. The ratio of misleading to leading distractors was 2:1 to reduce the likelihood that participants would intentionally attend to the distractors. Presentation of each problem as a control, misleading, or leading item was counterbalanced across participants in each age group and testing time.

\section{Procedure}

Half of the participants in each age group were randomly assigned to early morning testing (at $0800 \mathrm{~h}$ ), and half were randomly assigned to early evening testing (at $1700 \mathrm{~h}$ ), so that half the participants were tested at their peak time (i.e., young in the evening and old in the morning), and half at their off-peak time (i.e., young in the morning and old in the evening).

For the word problem task, participants were told that on each trial they would see three cue words that were all remotely associated to the same target, and that their job was to identify the target. Participants were then given an example problem and solution. Finally, participants were informed that on some trials, distractor words would appear directly below the cue words, and that these distractors would always disrupt the generation of the correct solution; thus participants were instructed to ignore the distractor items whenever they appeared. A sample problem with misleading distractors was then presented.

Each problem was presented individually on a computer screen for a maximum of $30 \mathrm{sec}$. The three cues were presented simultaneously from left to right in capital letters, and distractors, when present, appeared immediately below the cues in lowercase. Participants were informed that they had $30 \mathrm{sec}$ to generate the target aloud, and that if they failed to produce an answer within that time the computer would proceed to the next problem. If they produced an answer (either correct or incorrect), the experimenter pressed the space bar and the computer proceeded to the next trial. All responses were recorded by the experimenter.

Participants also completed a health and education question and Version 3 of the Extended Range Vocabulary Test (ERVT; Education Testing Service, 1976). Finally, they were questioned to determine whether they attempted to use the distractors in solving the word problems. No participant reported purposefully attending to the distractors for more than one trial.

\section{RESULTS}

\section{Participants}

For all analyses reported, the alpha level was set at .05 . Except where noted, a $2 \times 2$ analysis of variance (ANOVA) was employed, with age (young vs. old) and testing period (peak vs. off-peak) as between-subjects factors. Additionally, a Type III sums of squares analysis calculated by SAS was used because of the unequal number of observations in each cell. Four older adults ( 2 in the morning and 2 in the evening) failed to generate more than $10 \%$ of the targets in any condition, and their data were omitted from further analyses. The remaining older adults ( $M$ age $=67.1$ years) had an average of 14.8 years of education, a mean score of 27.4 on the ERVT, and an average MEQ score of 67.7 (range $=62-79$ ), which classified them as morning types. Younger adults ( $M$ age $=$ 18.6 years) had reliably less education $[M=12.2$ years, $\left.F(1,80)=38.3, M S_{\mathrm{e}}=244.7\right]$, a significantly lower ERVT score $\left[M=16.0, F(1,80)=39.1, M S_{\mathrm{e}}=3,908.1\right]$, and a lower score on the MEQ $[M=28.2$, range $=18-36$, $\left.F(1,80)=370.1, M S_{\mathrm{e}}=2,728.2\right]$, which classified them as evening types. There were no effects of testing period, and no age $\times$ testing period interactions on any of these variables.

\section{Word Problems}

Mean target identification rates for the control, misleading, and leading trials are displayed in Table 1. The first step in the analysis of problem-solving performance was to assess the target identification rates of control items only for younger and older adults over the day. To this end, a $2 \times 2$ ANOVA was conducted on target identification rates for control items only, with age (young vs. old) and testing period (peak vs. off-peak) as between-subjects factors. There were no main effects of age $[F(1,80)=0.1]$ or of testing period $[F(1,80)=1.3, p>.25]$; nor was the age $\times$ testing period interaction significant $[F(1,80)=$ 0.8 ]. Thus when no distraction was present, participants were equally capable of solving word problems at peak and off-peak times of day. Because the baseline control scores were equivalent for all groups, the remaining tests were calculated on cost and benefit scores.

The cost of misleading distractors and the benefit of leading distractors were calculated by subtracting the tar- 


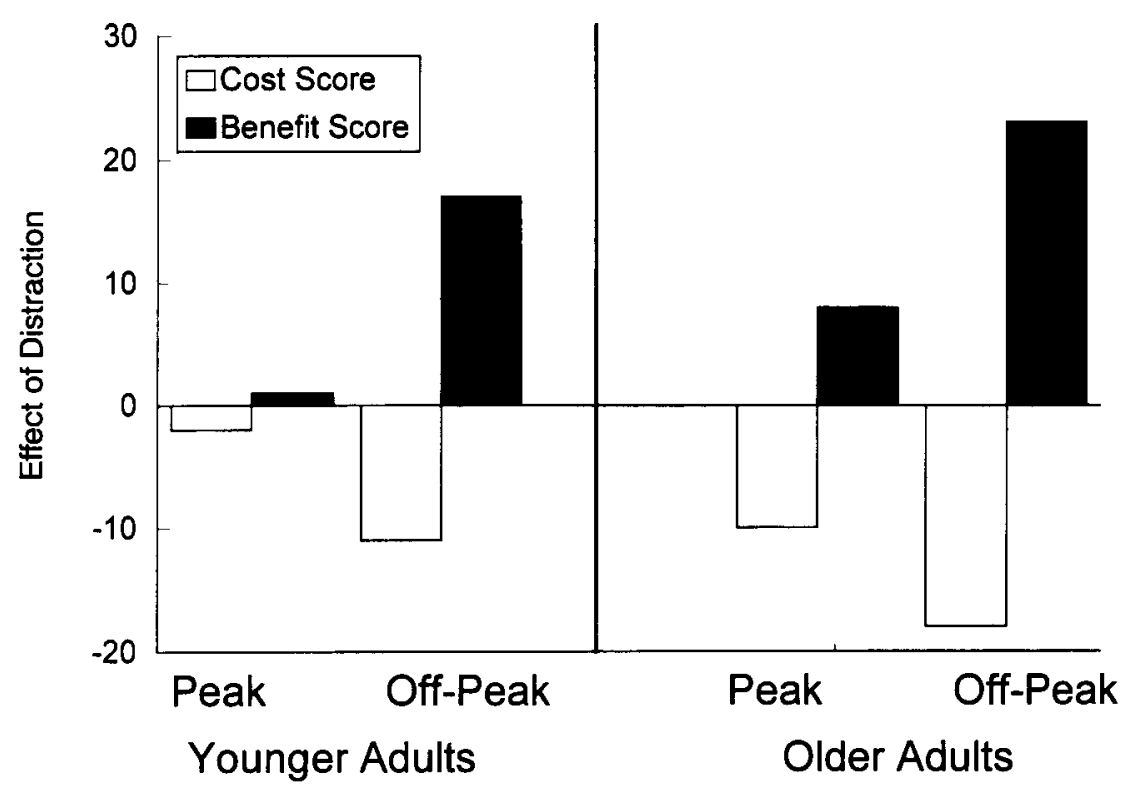

Figure 1. Mean cost (misleading - control) and benefit (leading - control) scores for younger and older adults tested at peak and off-peak times of day.

get identification rate for control trials from that of misleading and leading trials, respectively. Mean cost and benefit scores for each age group and testing period are depicted in Figure 1.

Consider first the cost effects, which were assessed with a 2 (testing period) $\times 2$ (age) ANOVA. There were main effects both of testing period $\left[F(1,80)=4.1, M S_{\mathrm{e}}=\right.$ $25,860.4]$ and of age $\left[F(1,80)=4.5, M S_{\mathrm{e}}=25,860.4\right]$; the cost of misleading distractors was higher for participants tested at off-peak relative to peak times of day, and for older relative to younger adults. The age $\times$ testing period interaction was not significant $[F(1,80)=0.1]$, indicating that the increase in costs from peak to off-peak times was similar across age groups.

To determine whether the cost scores were reliable for each age group and testing period, separate one-way ANOVAs were conducted for younger and older adults at peak and off-peak times. Results showed reliable cost scores for older adults tested at peak times $[F(1,21)=10.1$, $\left.M S_{\mathrm{e}}=179.7\right]$ and at off-peak times $[F(1,21)=73.1$, $\left.M S_{\mathrm{e}}=71.2\right]$. For younger adults, however, cost scores were significant only for those tested at off-peak times $\left[F(1,19)=5.4, M S_{\mathrm{e}}=244.7\right]$; younger adults tested at peak times showed no reliable cost of misleading distractors $[F(1,19)=0.2, p>.6]$.

Benefit effects were assessed with a 2 (testing period) $\times$ 2 (age) ANOVA, and the pattern of data was similar to that observed for cost effects. There was a main effect of testing period $\left[F(1,80)=11.1, M S_{\mathrm{e}}=39,755.9\right]$, with individuals tested at off-peak times showing larger benefits relative to agemates tested at peak times. The main effect of age failed to reach significance $[F(1,80)=2.2, p<.14]$, although the data were in the expected direction. Finally, the age $\times$ testing period interaction was not significant $[F(1,80)=0.4]$.

As for the cost effects, separate one-way ANOVAs were conducted for each age group and testing time to determine whether the benefit scores were reliable for younger and older adults tested at peak and off-peak times. The pattern was similar to that for the cost scores: For older adults, the benefit score was marginally reliable for those tested at peak times $[F(1,21)=3.2, p<.09]$ and highly significant for those tested at off-peak times $[F(1,21)=$ $\left.50.0, M S_{\mathrm{e}}=71.2\right]$. By contrast, only younger adults tested at off-peak times showed a significant benefit score $\left[F(1,19)=8.7, M S_{\mathrm{e}}=244.7\right]$; the benefit score for young adults at peak times was not significant $[F(1,19)=0.01$, $p>8$.

A final question of interest in this study concerned the magnitude of age differences over the day: Because younger and older adults differ in their peak performance periods, there is reason to suspect that age differences might vary as a function of when testing occurs. To explore this possibility, age differences were assessed separately for those participants tested in the morning and those tested in the evening. The data confirm the suspicion that age differences vary across the day: Separate one-way ANOVAs with age as the between-subjects factor indicated that for both the cost and benefit scores, age differences were reliable in the evening $\left[F(1,40)=8.6, M S_{\mathrm{e}}=\right.$ $25,860.4$, and $F(1,40)=11.7, M S_{\mathrm{e}}=39,755.9$, respectively], but were nonsignificant in the morning $[F(1,40)=$ 0.01 and $F(1,40)=1.7, p>.2$, respectively]. These findings indicate that the time at which participants are tested 
can dramatically affect the magnitude of the age differences observed, and indeed, whether age differences are observed at all.

\section{DISCUSSION}

It is now well established that the synchrony between peak circadian arousal periods and the time at which testing occurs can affect cognitive functioning in dramatic ways (see, e.g., Bodenhausen, 1990; May et al., 1993; Petros et al., 1990). However, until recently, little was known about the extent of synchrony effects in cognition--in particular, what types of processes are most vulnerable to variations in circadian arousal, and what processes, if any, are spared over the day. The present research joins with earlier work to suggest that the patterns of impaired versus preserved performance over the day are consistent with an inhibitory-deficit account of synchrony effects.

Two general patterns from the present study support an inhibitory view. First, in line with a number of recent findings (Intons-Peterson et al., 1998; May \& Hasher, 1998), the present data indicate that the ability to suppress irrelevant information diminishes at off-peak relative to peak times, as evidenced by reliably greater cost and benefit effects for participants tested at off-peak times. Second, the current findings join with other work to show that performance is spared over the day when tasks do not involve the suppression of irrelevant or previously relevant information, particularly when participants can rely on well-learned, semantic knowledge.

The present data are also consistent with other work showing a greater effect of distraction for older adults than for younger adults (e.g., Hasher et al., 1999; McDowd et al., 1995; Zacks et al., 1996). Older adults in this study showed significantly greater cost effects, and, although the age difference in benefit effects were not reliable, the data were in the expected direction, and the lack of reliability may stem in part from the relatively low number of leading trials. The general pattern supports the suggestion that one consequence of age-related inhibitory deficits is enhanced accessibility of distracting information. Particularly noteworthy is the finding that even when older adults were tested at their best time, they showed significant cost and benefit effects; by contrast, younger adults at their peak showed neither a reliable cost nor benefit effect, indicating that they were highly effective in suppressing off-task material at peak times. In assessing both age groups at their best time of day, then, there were considerable differences in inhibitory functioning. Note, however, that because younger and older adults have different peak periods, the magnitude of the age effect in inhibition varies over the day: In the evening, age differences in both cost and benefit effects were robust; however, in the morning, the pattern of performance for the two age groups was the same. These findings are consistent with others (see, e.g., May \& Hasher, 1998; May et al., 1993) in demonstrating that testing time may be a critical determinant of the pattern of age differences observed, particularly for tasks involving inhibition.

Several important theoretical and practical implications are suggested by this and related research. Because synchrony clearly influences the efficiency of inhibitory processes, investigators developing theories about the parameters of inhibition and its role in cognition must consider the interaction between circadian arousal and testing times. As evident in the present study, inhibitory processing can appear to be incredibly efficient or relatively ineffective, even within the same age group, depending on when testing occurs. Thus conclusions regarding inhibition, including its role in a given task and its efficiency within a particular cohort, may vary greatly if investigators disregard synchrony effects.

On a practical level, research on synchrony effects suggests recommendations for setting schedules and creating optimal work environments. Because suppression of off-task distractions will be particularly difficult at off-peak times, complex tasks that require forused attention (e.g., reading complex instructions), retrieval of exact information (e.g., recalling medication dosages), or careful control over responses (e.g., driving in heavy traffic) should be completed at peak hours or in a setting in which distractions are kept to a minimum. Empirical evidence supports these recommendations; studies show that college students tend to get higher grades when course schedules are in synch with individual differences in circadian arousal patterns (see, e.g., Frankel \& Lawrence, 1997; Guthrie, Ash, \& Bendapudi, 1995), and that older adults' prospective memory for medication adherence and appointments is better in the morning than in the afternoon or evening (Leirer, Tanke, \& Morrow, 1994).

On the positive side, the present work suggests that there are some instances in which individuals may benefit from reduced inhibitory efficiency, and thus performing at off-peak times may be preferable. Specifically, when distractions (e.g., conversations of co-workers or thoughts about marginally relevant ideas) prompt the correct solution, individuals can benefit from reduced inhibition. For example, in tasks requiring creative solutions, diminished inhibition may allow individuals to consider a greater breadth of alternatives and hence to produce better options. Of course, situations in which individuals are able to benefit from impaired inhibition may prove to be rare, but at present the possibilities remain to be explored.

\section{REFERENCES}

ADAN, A. (1991). Influence of morningness-eveningness preference in the relationship between body temperature and performance: $A$ diurnal study. Personality \& Individual Differences, 12, 1159-1169.

AdaN, A., \& AlmiralL, H. (1990). Adaptation and standardization of a Spanish version of the morningness-eveningness questionnaire: Individual differences. Personality \& Individual Differences, 11, 1123-1130

Bodenhausen, G. V. (1990). Stereotypes and judgmental heuristics: Evidence of circadian variation is discrimination. Psychological Science, 1, 319-322. 
Buela-Casal, G., Caballo, V. E., \& Cueto, E. (1990). Differences between morning and evening types in performance. Personality \& Individual Differences, 11, 447-450.

BURKE, D. M. (1997). Language, aging, and inhibitory deficits: Evaluation of a theory. Journal of Gerontology: Psychological Sciences, 52B, P254-P264.

Czeisler, C., Johnson, M., Duffy, J., \& Brown, E. (1990). Exposure to bright light and darkness to treat physiologic maladaption to night work. New' England Journal of Medicine, 322, 1253-1259.

Educational Testing Service (1976). Kit of factor-referenced cognitive tests. Princeton, NJ: Author.

Folkard, S., \& Monk, T. H. (1985). Hours of work: Temporal factors in work-scheduling. New York: Wiley.

Frankel, A., \& LaWrence, M. (1997, May). Do college students 'class schedules affect their grades?" "Early hirds" versus "night owls." Poster presented at the annual meeting of the American Psychological Society, Washington, DC.

Guthrie, J., Ash, R., \& Bendapudi, V. (1995). Additional validity evidence for a measure of morningness. Journal of Applied Psychology, 80, 186-190.

HASHER, L., \& ZACKS, R. T. (1988). Working memory, comprehension, and aging: $A$ review and a new view. In G. H. Bower (Ed.), The psychology of learning and motivation (Vol. 22, pp. 193-225). New York: Academic Press.

HASHER, L., ZACKS, R. T., \& MAY, C. P. (1999). Inhibitory control, circadian arousal, and age. In D. Gopher \& A. Koriat (Eds.), Attention and performance XVII: Cognitive regulation of performance: Interaction of theory and application. Cambridge. MA: MIT Press.

Horne, J., Brass, C., \& Pettitt, S. (1980). Circadian performance differences between morning and evening types. Ergonomics, 23, 29-36.

HORNE, J., \& OSTBERG, O. (1976). A self-assessment questionnaire to determine morningness-eveningness in human circadian rhythms. International Journal of Chronobiologl', 4, 97-110.

Hrushesky, W. (1994). Timing is everything. The Sciences, 3, 32-37.

Intons-Peterson, J. J., Rocchi. P.. West, T., MCLellan, K., \& HaCkNEY, A. (1998). Aging, optimal testing times, and negative priming. Joumal of Experimental Psycholog!: Learning, Memory: \& Cognition, 24. 362-376.

KERKHOF, G. A. (1984). A Dutch-language questionnaire for the selection of morning and evening type individuals. Nederlands Tijdschrift voor de Psychologie. 39. 281-294.

Kerkhof, G. A., van der Geest, W.. Korving, H. J., \& Rietveld, W. J. (1981). Diurnal differences between morning-type and evening-type subjects in some indices of central and autonomous nervous activity. In A. Reinberg, N. Vieux, \& P. Andlauer (Eds.), Night and shift work: Biological and social aspects (pp. 457-464). Oxford: Pergamon.

Leirer, V. O., TANKe, E. D.. \& Morrow, D. G. (1994). Time of day and naturalistic prospective memory. Experimental Aging Research. 20. 127-134.

Ll, K., Hasher, L., Jonas, D., Rahhal, T., \& May, C. P. (1998). Distractibility, aging, and circadian arousal: A boundary condition? Psychology \& Aging, 13, 574-583.

MAY, C. P.. \& HASHER, L. (1998). Synchrony effects in inhibitory control over thought and action. Journal of Experimental Psychology: Human Perception \& Performance. 24, 363-379.

May, C. P., Hasher, L.. \& Bhatt, A. (1994, April). Optimal time of dal and the Moses. Illusion effect with younger and older adults. Poster presented at the Cognitive Aging Conference. Atlanta.

May, C. P., Hasher, L., \& Stoltzfus, E. R. (1993). Optimal time of day and the magnitude of age differences in memory. Psychological Science, 4, 326-330.

May, C. P., Kane, M. J., \& Hasher, L. (1995). Determinants of negative priming. Psichological Bulletin, 118, 35-54.

McDowd. J., Oseas-Kreger, D., \& Filion, D. (1995). Inhibitory procession cognition and aging. In F. N. Dempster \& C. J. Brainerd (Eds.), Interference and inhibition in cognition (pp. 363-400). New York: Academic Press.

MECACC1. L.. \& ZANI. A. (1983). Morningness-eveningness preferences and sleep-waking diary data of morning and evening types in student and worker samples. Ergonomics, 26, I147-1153.

Mecacci, L., Zani, A., Rocchetti, G., \& Lucioli, R. (1986). The rela- tionships between morningness-eveningness, ageing and personality. Personality \& Individual Differences, 7, 911-913.

Mednick, S. A. (1962). The associative basis of the creative process. Psychological Review, 69, 220-232.

Moore-Ede, M., Czeisler, C., \& Richardion, J. (1983). Circadian timekeeping in health and disease: I. Basic properties of circadian pacemakers. New England Journal of Medicine, 309, 469-476.

NAVON, D. (1989a). The importance of being visible: On the role of attention in a mind viewed as an anarchic intelligence system: 1. Basic tenets. European Journal of Cognitive Psychology, 1, 191-213.

NAVON, D. (1989b). The importance of being visible: On the role of attention in a mind viewed as an anarchic intelligence system: II. Application to the field of attention. European Journal of Psychology, 1, 215-238.

NeILl, W. T. (1977). Inhibition and facilitation processes in selective attention. Journal of Experimental Psychology: Human Perception \& Performance, 3, 444-450.

NeILL. W. T., \& Valdes, L. A. (1996). Facilitatory and inhibitory aspects of attention. In A. F. Kramer, M. Coles, \& G. D. Logan (Eds.), Converging operations in the study of visual selective attention (pp. 77106). Washington, DC: American Psychological Association.

Park, J., \& Kanwisher, N. (1994). Negative priming for spatial location: Identity mismatching, not distractor inhibition. Journal of Experimental Psychology: Human Perception \& Performance, 20, 613-623.

Petros, T. V., Beckwith, B. E., \& Anderson, M. (1990). Individual differences in the effects of time of day and passage difficulty on prose memory in adults. British Journal of Psychology, 81, 63-72.

Smith, C. S., ReIlly, C., \& MidkifF, K. (1989). Evaluation of the circadian rhythm questionnaires with suggestions for an improved measure of morningness. Journal of Applied Psychology, 74, 728-738.

SMITH, S. M., \& BlankENSHIP, S. E. (1991). Incubation and the persistence of fixation in problem solving. American Journal of Psychology, 104, 61-87.

SMOLENSKY, M., \& D Alonzo, G. (1993). Medical chronobiology: Concepts and applications. American Review of Respiratory Disease, 147, S2-S19.

StroOP, J. R. (1935). Studies of interference in serial verbal reactions. Journal of Experimental Psychology, 18, 643-662.

YOON, C. (1997). Age differences in consumers' processing strategies: An investigation of moderating influences. Journal of Consumer Research, 24, 329-342.

YoON, C., MAY, C. P., \& Hasher, L. ( 1999). Aging, circadian arousal patterns, and cognition. In N. Schwarz, D. Park, B. Knäuper, \& S. Sudman (Eds.), Cognition, aging, and survey measurement. New York: Jossey-Bass.

Zacks, R. T., Radvansky, G. A., \& Hasher, L. (1996). Studies of directed forgetting in older adults. Journal of Experimental Psychology: Leaming, Memory: \& Cognition, 22, 143-156.

\section{NOTES}

1. The finding of variations in negative priming over the day should be interpreted with caution since recent investigations have questioned the validity of negative priming as a measure of inhibition (see May, Kane, \& Hasher, 1995, for a review), and a number of alternative mechanisms have been offered as sources for the negative priming effect (see, e.g., Neill \& Valdes, 1996; Park \& Kanwisher, 1994).

2. One notable exception to this pattern of impaired inhibition at offpeak times is the finding that there is no effect of synchrony on the ability to read and comprehend text in the face of distraction ( $\mathrm{Li}$, Hasher, Jonas, Rahhal, \& May, 1998). As Li et al. noted, differences in task difficulty and participant expertise may account for this discrepancy. Most of the tests used to assess synchrony are quite challenging, and individuals have little or no prior experience with them (e.g., negative priming. Stroop color naming); however, reading in the face of verbal distraction is a familiar, everyday task (consider newspapers, for example). It is possible that practice or expertise provides a boundary condition for synchrony effects.

(Manuscript received September 22, 1997: revision accepted for publication March 5, 1998.) 